\title{
Is Preoperative Pyuria Associated with Postoperative Febrile Complication after Ureteroscopic Ureter or Renal Stone Removal?
}

\author{
Seungsoo Lee \\ Department of Urology, Pusan National University Yangsan Hospital, Yangsan, Korea
}

Purpose: The association between preoperative pyuria and postoperative febrile complications after ureteroscopic ureter or renal stone removal was examined. Materials and Methods: From June 2014 to July 2016, 110 patients who underwent ureteroscopic ureter or renal stone removal by a single surgeon were evaluated. The patients were categorized as the "pyuria group" and "nonpyuria group." The sex, age, stone laterality, stone location, stone size, preoperative urine culture results, and postoperative complications in each group were analyzed.

Results: The pyuria and nonpyuria groups were comprised of 55 patients each. The mean ages the pyuria and nonpyuria groups were $58.4 \pm 16.1$ years and $54.4 \pm 13.2$ years, respectively. There were respectively, 43 and 12 unilateral and bilateral stones in the pyuria group, and 53 and two in the nonpyuria group. The stone sizes of the pyuria and nonpyuria groups were $13.1 \pm 5.4 \mathrm{~mm}$ and $11.1 \pm 4.7 \mathrm{~mm}$, respectively. The pyuria group contained more patients with bilateral stones and larger stones than the nonpyuria group. Five and two postoperative febrile complications were encountered in the pyuria group and the nonpyuria group, respectively. No significant difference in febrile complications was observed between the two groups. In logistic regression analysis, bilateral stones and larger stones were associated with pyuria.

Conclusions: In ureteroscopic stone removal surgery, preoperative pyuria was associated with bilateral and larger stones, but there were no associations with febrile complications.

Keywords: Pyuria; Ureteral calculi; Ureteroscopy; Fever

Copyright @ 2020, Korean Association of Urogenital Tract Infection and Inflammation. All rights reserved. (c) (1) (s) This is an open access article distributed under the terms of the Creative Commons Attribution (C) (1) (5) Non-Commercial License (http://creativecommons.org/licenses/by-nc/4.0) which permits unrestricted non-commercial use, distribution, and reproduction in any medium, provided the original work is properly cited.
Received: 27 December, 2019

Revised: 10 February, 2020

Accepted: 14 April, 2020

\section{INTRODUCTION}

Ureteral and renal stones are a clinically important disease in the urological field because they can result in several complications, including pain, renal function deterioration, inflammation, and fever. Urinary obstruction with urinary stones is the most common cause of urosepsis [1,2]. Therefore, urinary stones need to be removed to prevent and relieve urinary obstructions, particularly to prevent infectious complications.

The management of kidney and ureteral stones has improved with endoscopic techniques, such as ureteroscopy (URS), which is the most common therapeutic procedure [3]. Several reports have revealed high success rates and low complication rates involved in undergoing ureteroscopic surgery for urinary stones [4-8]. De la Rosette et al. [7] analyzed 11,885 patients treated with URS between 2010 and 2012 using the Clinical Research Office of the 
Endourological Society (CROES) database, which collected data from 114 centers in 32 countries. The authors reported that the stone-free rate was $85.6 \%$, with a postoperative complication rate of $3.5 \%$; fever was the most frequent complication (2.8\%).

Although ureteroscopic stone removal is a safe and effective technique, postoperative complications, particularly febrile urinary tract infection (UTI), can occur. Daels et al. [9] reported that certain risk factors, including diabetes mellitus, anticoagulation use, cardiovascular disease, or obesity, were associated with complications.

On the other hand, the factors associated with postoperative infectious complications after ureteroscopic stone removal have not been examined in detail [10]. Therefore, this study examined the association between preoperative pyuria and postoperative febrile complications after the ureteroscopic removal of ureter or renal stones.

\section{MATERIALS AND METHODS}

From June 2014 to July 2016, 114 patients, who underwent semirigid, flexible ureteroscopic ureter, or renal stone removal by a single surgeon (Seungsoo Lee), were evaluated. Four patients with anuria due to bilateral ureteral stones were excluded. The patients were categorized as the "pyuria group" and "nonpyuria group." Sex, age, stone laterality (unilateral or bilateral), stone location (kidney, upper, mid, or lower ureter), stone size, preoperative urine culture results, and postoperative complications were analyzed. Pyuria was defined as the presence of six or more white cells per high-power field in a urine specimen. If a patient had multiple stones, the laterality, location, and the size of the largest stone were analyzed.

Statistical analyses were performed using IBM SPSS Statistics version 20.0 (IBM Corp., Armonk, NY, USA), and p-values $<0.05$ were considered significant. A student's t-test and Pearson's chi-square test were applied to assess the differences between the groups. Logistic regression analysis was applied to evaluate the factors related to pyuria.

\section{RESULTS}

The pyuria group and nonpyuria group each comprised 55 patients: 34 males and 21 females in the pyuria group and 36 males and 19 females in the nonpyuria group. The mean age in the pyuria group and nonpyuria group was $58.4 \pm 16.1$ years and $54.4 \pm 13.2$ years, respectively. In the pyuria group, 43 patients had unilateral stones, and 12 had bilateral stones. In the nonpyuria group, there were 53 patients with unilateral stones and two with bilateral stones. The stones were located in the kidney, upper, mid, and lower ureter in 13, 28, 8, and 6 patients in the pyuria group, respectively, and $14,23,6$, and 12 patients in the nonpyuria group, respectively. The largest stone size in the pyuria group and nonpyuria group was $13.1 \pm 5.4 \mathrm{~mm}$ and $11.1 \pm 4.7 \mathrm{~mm}$, respectively (Table 1 ).

No statistical differences in sex, age, and stone location were observed between the two groups $(p=0.692, p=0.157$, and $\mathrm{p}=0.421$, respectively). On the other hand, the stone laterality and size differed significantly between the two groups ( $p=0.004$ and $p=0.036$, respectively). The pyuria group had more patients with bilateral stones and larger stones than the nonpyuria group (Table 1).

From the preoperative urine culture, uropathogens were identified in only six cases (10.9\%) in the pyuria group and five cases (9.1\%) in the nonpyuria group. In the pyuria group, Escherichia coli (non-extended-spectrum beta-lactamases [non-ESBL]) was identified in three cases, and E. coli (ESBL), Streptococcus agalactiae, and Staphylococcus epidermidis were identified in one case each. In the nonpyuria group, E. coli (non-ESBL), E. coli (ESBL), S. agalactiae, Enterococcus faecalis, and yeast-like cells were identified in one case each (Table 1).

Postoperative complications in the pyuria group were fever in five patients $(9.1 \%)$, gastrointestinal problems in two patients (3.6\%), ureteral injury in two cases (3.6\%), cardiovascular complication in one patient (1.8\%), and urinary retention in one case (1.8\%). In the nonpyuria group, the complications were fever in two patients (3.6\%), pain in two cases (3.6\%), ureteral injury in two patients (3.6\%), and bleeding in two cases (3.6\%). No significant difference in febrile complications was observed between the two groups $(\mathrm{p}=0.241)$ (Table 2$)$.

Logistic regression analysis revealed only stone laterality and stone size to be associated with preoperative pyuria. Bilateral stones and larger stones are tended to show preoperative pyuria (Table 3). 
Table 1. Characteristics of the patients and stones in the pyuria and nonpyuria group

\begin{tabular}{|c|c|c|c|}
\hline Characteristic & Pyuria group $(n=55)$ & Nonpyuria group $(n=55)$ & $\mathrm{p}$-value \\
\hline Sex & & & 0.692 \\
\hline Male & $34(61.8)$ & $36(65.5)$ & \\
\hline Female & $21(38.2)$ & 19 (34.5) & \\
\hline Mean age (y) & $58.4 \pm 16.1(26-89)$ & $54.4 \pm 13.2(18-80)$ & 0.157 \\
\hline Stone laterality & & & 0.004 \\
\hline Unilateral & $43(78.2)$ & $53(96.4)$ & \\
\hline Bilateral & $12(21.8)$ & $2(3.6)$ & \\
\hline Stone location & & & 0.421 \\
\hline Kidney & $13(23.6)$ & $14(25.5)$ & \\
\hline Upper ureter & $28(50.9)$ & $23(41.8)$ & \\
\hline Mid ureter & $8(14.5)$ & $6(10.9)$ & \\
\hline Lower ureter & $6(10.9)$ & $12(21.8)$ & \\
\hline Stone size $(\mathrm{mm})$ & $13.1 \pm 5.4(4.0-25.0)$ & $11.1 \pm 4.7(4.0-26.0)$ & \\
\hline Preoperative urine culture & & & 0.036 \\
\hline Escherichia coli (non-ESBL) & 3 & 1 & \\
\hline Escherichia coli (ESBL) & 1 & 1 & \\
\hline Streptococcus agalactiae & 1 & 1 & \\
\hline Staphylococcus epidermidis & 1 & 0 & \\
\hline Enterococcus faecalis & 0 & 1 & \\
\hline Yeast like cell & 0 & 1 & \\
\hline
\end{tabular}

Values are presented as number (\%), mean \pm standard deviation (range), or number only.

Table 2. Perioperative complications in the pyuria and nonpyuria group

\begin{tabular}{lccc}
\hline \multicolumn{1}{c}{ Complications } & $\begin{array}{c}\text { Pyuria group } \\
(\mathrm{n}=55)\end{array}$ & $\begin{array}{c}\text { Nonpyuria group } \\
(\mathrm{n}=55)\end{array}$ & p-value \\
\hline Fever & $5(9.1)$ & $2(3.6)$ & 0.241 \\
Pain & $0(0.0)$ & $2(3.6)$ & \\
Gastrointestinal problem & $2(3.6)$ & $0(0.0)$ & \\
Ureteral injury & $2(3.6)$ & $2(3.6)$ & \\
Cardiac complication & $1(1.8)$ & $0(0.0)$ & \\
Bleeding & $0(0.0)$ & $1(1.8)$ & \\
Urinary retention & $1(1.8)$ & $0(0.0)$ & \\
\hline
\end{tabular}

Values are presented as number (\%).

\section{DISCUSSION}

Ureteroscopic stone removal is the most widely used surgical treatment method because of its effectiveness and low complication rate. In addition, it has no specific contraindications and can be used for most patients with urinary stones [11]. Decompression for urinary obstruction with ureteroscopic stone removal is important for preventing or relieving urinary infection or urosepsis. On the other hand, postoperative fever is the most frequent complication of ureteroscopic surgery, and it is important to identify patients at risk of developing infectious complications from surgery $[7,10,12]$.

Several studies have examined postoperative febrile UTI after ureteroscopic stone removal. Mitsuzuka et al. [10] reported that $18.3 \%$ of 182 patients had postoperative febrile UTI. Sohn et al. [13] analyzed 531 patients who underwent diagnostic URS or ureteroscopic stone removal and reported
Table 3. Logistic regression analysis of the parameters related to pyuria

\begin{tabular}{lccccc}
\hline \multicolumn{1}{c}{ Parameters } & $\mathrm{B}$ & $\mathrm{SE}$ & $\operatorname{Exp}(\mathrm{B})$ & $95 \% \mathrm{Cl}$ & $\mathrm{p}$-value \\
\hline Stone laterality & -1.987 & 0.797 & 0.137 & $0.029-0.645$ & 0.013 \\
Stone size & -0.080 & 0.041 & 0.923 & $0.852-1.000$ & 0.049
\end{tabular}

SE: standard error, $\operatorname{Exp}(\mathrm{B})$ : odds ratio, $\mathrm{Cl}$ : confidence interval.

that $3.8 \%$ of patients had infectious complications. In the present study, seven (6.4\%) out of 110 patients experienced postoperative fever.

Severe postoperative complications associated with fever, including sepsis, have also been reported, with patients having to undergo special therapies and interventions [10,11]. Fortunately, in the present study, all the postoperative complications were Grade I under the modified Clavien-Dindo grading system [14]. The patients who had fever were treated with medication, including nonsteroidal anti-inflammatory drugs or acetaminophen.

This study examined the relationship between preoperative pyuria and postoperative febrile complications. Mitsuzuka et al. [10] reported preoperative pyuria and acute pyelonephritis to be significant risk factors for postoperative febrile UTI. Moreover, the degree of preoperative pyuria was likely to be associated with postoperative febrile UTI. In the present study, however, pyuria was not associated with postoperative febrile UTI. Although there were more patients with postoperative fever in the pyuria group (five cases) than in the nonpyuria group (two cases), the difference was not statistically significant. In addition, pyuria in urinary 
stone patients does not always associate with UTI. Urinary stone disease at any level might increase the number of urinary leukocytes caused by stasis-induced ascending infection or localized mucosal inflammatory response [15].

Prophylactic antibiotic therapy may be an important factor for UTI. The use of prophylactic antibiotics in patients undergoing urologic procedures can reduce the incidence of postoperative infectious complications [16-19]. In the present study, all the patients had undergone pre- and postoperative antibiotic treatment. Most patients had cefmetazole (2nd cephalosporin), but other antibiotics were used if a patient had an allergic reaction to cephalosporin or if uropathogens and a resistance pattern were identified from the urine culture. The antibiotic agent, dose, and duration in each patient were not analyzed. Therefore, the difference in antibiotic regimen is one of the limitations in this report.

$E$. coli is the most common bacterial pathogen associated with urinary infections [20], and in this study, E. coli was also the most identified pathogen; among the six $E$. coli-identified specimens, two were ESBL.

Six or seven Fr double-J ureteral stents were inserted in the ureter at the end of each surgery. Ureteral stents were inserted in both ureters if a patient had bilateral ureteral stones. The stent was removed after 2 to 4 weeks postoperatively. Another potential limitation was the lack of an evaluation of ureteral stenting duration and laterality.

\section{CONCLUSIONS}

In ureteroscopic stone removal surgery, preoperative pyuria was related to bilateral stones and larger stones, but febrile complications were not associated with preoperative pyuria. With appropriate prophylactic antibiotics and postoperative care, ureteroscopic stone removal can be used for patients with preoperative pyuria.

\section{CONFLICT OF INTEREST}

No potential conflict of interest relevant to this article was reported.

\section{ACKNOWLEDGMENTS}

This study was supported by a 2017 research grant from
Pusan National University Yangsan Hospital.

\section{REFERENCES}

1. Wagenlehner FM, Lichtenstern C, Rolfes C, Mayer K, Uhle F, Weidner W, et al. Diagnosis and management for urosepsis. Int J Urol 2013;20:963-70.

2. Wagenlehner FM, Pilatz A, Weidner W. Urosepsis--from the view of the urologist. Int J Antimicrob Agents 2011;38 Suppl:51-7.

3. Zanetti G, Paparella S, Trinchieri A, Prezioso D, Rocco F, Naber KG. Infections and urolithiasis: current clinical evidence in prophylaxis and antibiotic therapy. Arch Ital Urol Androl 2008;80:5-12.

4. Preminger GM, Tiselius HG, Assimos DG, Alken P, Buck AC, Gallucci M, et al.; American Urological Association Education and Research, Inc; European Association of Urology. 2007 Guideline for the management of ureteral calculi. Eur Urol 2007; 52:1610-31.

5. Bader MJ, Eisner B, Porpiglia F, Preminger GM, Tiselius HG. Contemporary management of ureteral stones. Eur Urol 2012;61:764-72.

6. Geavlete P, Georgescu D, Niţă G, Mirciulescu V, Cauni V. Complications of 2735 retrograde semirigid ureteroscopy procedures: a single-center experience. J Endourol 2006;20:179-85.

7. De la Rosette J, Denstedt J, Geavlete P, Keeley F, Matsuda T, Pearle $M$, et al.; CROES URS Study Group. The Clinical Research Office of the Endourological Society ureteroscopy global study: indications, complications, and outcomes in 11,885 patients. J Endourol 2014;28:131-9.

8. Rippel CA, Nikkel L, Lin YK, Danawala Z, Olorunnisomo V, Youssef RF, et al. Residual fragments following ureteroscopic lithotripsy: incidence and predictors on postoperative computerized tomography. J Urol 2012;188:2246-51.

9. Daels FP, Gaizauskas A, Rioja J, Varshney AK, Erkan E, Ozgok Y, et al. Age-related prevalence of diabetes mellitus, cardiovascular disease and anticoagulation therapy use in a urolithiasis population and their effect on outcomes: the Clinical Research Office of the Endourological Society ureteroscopy global study. World J Urol 2015;33:859-64.

10. Mitsuzuka K, Nakano O, Takahashi N, Satoh M. Identification of factors associated with postoperative febrile urinary tract infection after ureteroscopy for urinary stones. Urolithiasis 2016;44:257-62.

11. Youssef RF, Neisius A, Goldsmith ZG, Ghaffar M, Tsivian M, Shin $\mathrm{RH}$, et al. Clinical outcomes after ureteroscopic lithotripsy in patients who initially presented with urosepsis: matched pair comparison with elective ureteroscopy. J Endourol 2014;28: 1439-43.

12. Özsoy M, Acar Ö, Sarica K, Saratlija-Novakovic Z, Fajkovic H, 
Librenjak D, et al. Impact of gender on success and complication rates after ureteroscopy. World J Urol 2015;33: 1297-302.

13. Sohn DW, Kim SW, Hong CG, Yoon BI, Ha US, Cho YH. Risk factors of infectious complication after ureteroscopic procedures of the upper urinary tract. J Infect Chemother 2013;19:1102-8.

14. Dindo D, Demartines N, Clavien PA. Classification of surgical complications: a new proposal with evaluation in a cohort of 6336 patients and results of a survey. Ann Surg 2004;240: 205-13.

15. Riley RS, McPherson RA. Basic examination of urine. In: McPherson RA, Pincus MR, editors. Henry's clinical diagnosis and management by laboratory methods. 23rd ed. St. Louis: Elsevier; 2017. p. 462.

16. Amin M. Antibacterial prophylaxis in urology: a review. Am J
Med 1992;92:114S-7S

17. Klimberg IW, Malek GH, Cox CE, Patterson AL, Whalen E, Kowalsky SF, et al. Single-dose oral ciprofloxacin compared with cefotaxime and placebo for prophylaxis during transurethral surgery. J Antimicrob Chemother 1999;43 Suppl A:77-84.

18. Kapoor DA, Klimberg IW, Malek GH, Wegenke JD, Cox CE, Patterson $A L$, et al. Single-dose oral ciprofloxacin versus placebo for prophylaxis during transrectal prostate biopsy. Urology 1998;52:552-8.

19. Charton M, Vallancien G, Veillon B, Brisset JM. Antibiotic prophylaxis of urinary tract infection after transurethral resection of the prostate: a randomized study. J Urol 1987; 138:87-9.

20. Ronald A. The etiology of urinary tract infection: traditional and emerging pathogens. Am J Med 2002;113 Suppl 1A:14S-9S. 